\title{
Immunogold Localization of p55-Fibril Protein and p25-Spiralin in Spiroplasma Cells
}

\author{
By R. TOWNSEND* AND K. A. PLASKITT \\ John Innes Institute, Colney Lane, Norwich NR4 7UH, UK
}

(Received 14 November 1984)

\begin{abstract}
Transmission electron microscopy of thin sectioned cells of the honeybee spiroplasma BC3 revealed evidence of a helically twisted ribbon closely associated with the cytoplasmic surface of the plasma membrane. The cellular distribution of p55-fibril protein as demonstrated by immunogold staining with anti-p55 antibody was consistent with the presence of p55 in this ribbon. We conclude that spiroplasma fibrils are arranged in a single helically twisted ribbon rather than forming a contractile sheath or branched axial fibre. Immunogold staining with antip25-spiralin antibody confirmed that this protein is localized in the plasma membrane and also showed that it occurs in extracellular strands. These strands may be antigenically distinct from the integral form of the protein.
\end{abstract}

\section{INTRODUCTION}

Spiroplasmas contain long flexuous fibrils $3.6 \mathrm{~nm}$ in diameter and several $\mu \mathrm{m}$ in length which are composed of a protein of mol. wt 55000 (p55) (Townsend et al., 1980a). This polypeptide is highly conserved among members of the genus Spiroplasma and comprises between 0.5 and $3 \%$ of total cell protein in different species (Townsend \& Archer, 1983). It has been suggested that these fibrils may form part of a contractile peripheral sheath (Razin, 1978; Townsend et al., $1980 a, b)$ or a branched 'cytoskeleton' (Wilson \& Goodman, 1982) which is responsible for maintaining the helical shape of these wall-less prokaryotes and generating the twisting movements which characterize their motility. However, it has not been possible to demonstrate the cellular organization of the fibrils and to determine if it is compatible with their proposed function. Fibrils could not be resolved in thin sections of spiroplasmas fixed under conditions regarded as optimal for the preservation of helicity (Cole et al., 1973) or in replicas of freezecleaved cells (Razin et al., 1973). Kleinschmidt spreads of osmotically sensitized cells indicated that the fibrils might be organized into a single fibre bundle or ribbon in the intact spiroplasma (Townsend, 1983a), but attempts to confirm this arrangement by immuno-localization of fibrils in cell sections have been frustrated because purified fibrils associate into large aggregates which are highly resistant to dissociation (Townsend et al., 1980a) and fail to elicit detectable antibodies (unpublished results). Although purified fibrils could be solubilized in SDS, antibodies elicited against the detergent-solubilized p55 only reacted with denatured protein (Townsend \& Archer, 1983). We report here the production of an antibody which specifically recognizes denatured p55 on blots but also reacts with native fibrils, and its use in an immunogold staining procedure to demonstrate the cellular organization of spiroplasma fibrils.

We have also used immunogold staining to investigate the distribution of a protein (p25) with a molecular weight of 25000 , which is the major membrane protein of spiroplasma BC3 (Archer \& Townsend, 1981), and which is related to the spiralin protein of Spiroplasma citri (Wróblewski et al., 1977).

Abbreviations: DMAA, 2,3-dimethylmaleic anhydride; TB, 15 mM-Tris/HCl buffer; TBS, TB buffer containing $\mathrm{NaCl}$. 


\section{METHODS}

Culture of spiroplasmas. The honeybee spiroplasma BC3 was obtained from T. B. Clark, USDA, Beltsville, Md, USA and was grown in SMC medium (Markham et al., 1974) supplemented with $10 \%(\mathrm{v} / \mathrm{v})$ foetal calf serum. Cells were harvested in the late exponential phase of growth by centrifugation $\left(15000 \mathrm{~g}, 15 \mathrm{~min}, 4^{\circ} \mathrm{C}\right)$ and resuspended very gently at $4{ }^{\circ} \mathrm{C}$ in a quarter volume of $15 \mathrm{~mm}$-Tris/ $\mathrm{HCl}$ buffer $\mathrm{pH} 7.5(\mathrm{~TB})$ containing $7 \%(\mathrm{w} / \mathrm{v})$ sorbitol and $0.1 \%$ fructose to give a washed cell suspension.

Fixation of spiroplasmas with glutaraldehyde or paraformaldehyde. Ice-cold glutaraldehyde $(12 \cdot 5 \%$, w/v) or freshly generated paraformaldehyde $(10 \%, \mathrm{w} / \mathrm{v})$ in $0.2 \mathrm{M}$-cacodylate buffer $\mathrm{pH} 7.0$ containing $7 \%(\mathrm{w} / \mathrm{v})$ sorbitol was added to an equal volume of washed cell suspension and the mixture incubated on ice for $1 \mathrm{~h}$. Fixed spiroplasmas were collected by centrifugation, washed in TB and then sedimented by centrifugation. The pellets were resuspended in a one-tenth starting volume of TB to give a fixed cell suspension containing about $10^{10} \mathrm{cells}^{-1}$.

Dissociation of spiroplasma fibrils by maleylation. Fibrils $(8 \mathrm{mg})$ purified from spiroplasma BC 3 by the method of Townsend et al. (1980a) were resuspended in $50 \mathrm{~mm}$-HEPES pH 8.2 containing $30 \mathrm{mg}$ of the protein dissociating reagent 2,3-dimethylmaleic anhydride (DMMA; Aldrich) (Butler et al., 1967; Gertler, 1971) and stirred for $4 \mathrm{~h}$ at $20{ }^{\circ} \mathrm{C}$. Since maleylation is accompanied by the release of hydrogen ions, the $\mathrm{pH}$ was maintained above 8.0 by addition of $5 \mathrm{M}-\mathrm{KOH}$. the reaction mixture was then centrifuged $\left(180000 \mathrm{~g}, 1 \mathrm{~h}, 4{ }^{\circ} \mathrm{C}\right)$ to remove undissociated protein and the pellet was dried and weighed to determine, by difference, the amount of dissociated protein. Since it has been shown that maleylation of enzymes is reversible, hydrolysis of the maleylamino bonds resulting in complete restoration of enzyme activity (Gertler, 1971; Palacián, 1979), we considered it probable that the maleylated fibril protein would retain epitopes characteristic of the native protein particularly if the reaction could be demonstrably reversed by reconstitution of intact fibrils. To investigate the reversibility of the reaction a small sample of the clear supernatant containing the solubilized protein was removed and the 2,3-dimethylmaleylamino bonds were hydrolysed (Butler et al., 1967; Dixon \& Perham, 1968) by lowering the pH to 6.0 with $1 \mathrm{M}$-sodium cacodylate buffer and incubating for $4 \mathrm{~h}$ at $37^{\circ} \mathrm{C}$. The reaction mixture was centrifuged and the composition of the pellet investigated by electron microscopy and SDS-polyacrylamide gel electrophoresis (PAGE) (see below). The remainder of the bulk supernatant containing soluble 2,3-dimethyl-methylated protein was dialysed overnight at $4{ }^{\circ} \mathrm{C}$ against $25 \mathrm{~mm}$-Tris/ $\mathrm{HCl}$ buffer $\mathrm{pH} 8.2$ to remove hydrolysed reagent.

Production of anti-p55 antibody. Immediately after dialysis the preparation of dissociated fibrils was emulsified with an equal volume of Freund's incomplete adjuvant and injected subcutaneously into a New Zealand White rabbit. A further injection of freshly prepared antigen was made after 3 weeks and the animal was bled 2 weeks later. The immune serum, hereafter referred to as anti-p 55 serum, was divided into aliquots and stored at $-20^{\circ} \mathrm{C}$.

Cross-adsorbed anti-p55 serum that was free of antibodies elicited against cell surface antigens, hereafter referred to as anti-p 55 antibody, was obtained by mixing $0.1 \mathrm{ml}$ anti-p 55 serum with $3 \mathrm{ml}$ glutaraldehyde fixed cell suspension in $\mathrm{TB}$ containing $0.9 \% \mathrm{NaCl}$ (TBS). After incubation at $4{ }^{\circ} \mathrm{C}$ for $16 \mathrm{~h}$ with continuous agitation, the cells with bound antibody were removed by centrifugation and the resulting anti-p 55 antibody stored in aliquots at $-20^{\circ} \mathrm{C}$.

Anti-p25 antibody which reacted specifically with the $25000 \mathrm{~mol}$. wt spiralin-like protein of BC3, as demonstrated by cross-immunoelectrophoresis (Archer \& Townsend, 1981), was prepared using p25-spiralin purified by agarose suspension electrophoretic separation of sodium deoxycholate soluble BC 3 membrane proteins (Archer \& Townsend, 1981).

The stated dilution factors represent the overall dilution relative to original serum.

Immunodiffusion and spiroplasma deformation. The activity of the antiserum was monitored by double immunodiffusion (Crowle, 1961) against DMMA dissociated fibrils, SDS solubilized fibrils and SDS solubilized total BC3 cell proteins. The presence of antibodies reacting with cell surface antigens was investigated using the spiroplasma deformation test (Williamson et al., 1978).

Immuno-ferritin localization of cell surface antigens on fixed spiroplasmas. To examine the distribution of cell surface antigens, whose presence was indicated by high cell deformation titres, anti-p 55 serum was added, before and after cross-adsorption against fixed cells, or anti-p 25 antibody, to glutaraldehyde fixed cell suspensions to give a final dilution of 1 in 100 . After $30 \mathrm{~min}$ at $37^{\circ} \mathrm{C}$, goat anti-rabbit IgG-ferritin (Miles Laboratories, Slough, UK) was added to a dilution of 1 in 100 . After a further $30 \mathrm{~min}$ at $37^{\circ} \mathrm{C}$, the cells were collected by centrifugation, washed twice in TB and observed by transmission electron microscopy without negative staining.

Immuno-ferritin labelling of native 55 in Kleinschmidt spreads of spiroplasma cell contents. In order to confirm that the anti-p55-antibody recognized native protein, the antibody was used to label fibrils released from lysed cells. To facilitate lysis, glycerol $(10 \%, \mathrm{v} / \mathrm{v})$ was added to $1 \mathrm{ml}$ washed cell suspension which was incubated for $30 \mathrm{~min}$ at $4{ }^{\circ} \mathrm{C}$. Drops of the osmotically sensitized cell suspension were then applied to glass distilled water essentially according to the one-step release method of Kleinschmidt (1968) but without addition of cytochrome $c$. Cell spreads were collected on carbon-coated parlodion support films and floated on drops of TBS containing $1 \%(w / v)$ bovine serum albumin (BSA) for $10 \mathrm{~min}$ to block protein binding sites. The cell spreads were then transferred to TB containing BSA and a 1 in 30 or 1 in 100 dilution of anti-p55 antibody or a 1 in 100 dilution of anti-p25 
antibody, incubated for $1 \mathrm{~h}$ at $20^{\circ} \mathrm{C}$ and then washed on drops of TB. The washed cell spreads were then floated on a 1 in 50 dilution of goat anti-rabbit IgG-ferritin in TBS for $30 \mathrm{~min}$, washed 10 times in drops of TB and finally negatively stained with uranyl acetate.

Immuno-ferritin localization of p55 in fixed, detergent extracted cells. To investigate if spiroplasma cells could be made permeable to antibodies in order to reveal the intracellular arrangement of fibrils, paraformaldehyde fixed cells were treated with $0 \cdot 1 \%$ SDS or $0 \cdot 1 \%$ Triton X-100 for $1 \mathrm{~h}$ at $4{ }^{\circ} \mathrm{C}$. The detergent extracted cells were processed as described for the immuno-ferritin localization of cell surface antigens on fixed cells or examined by transmission electron microscopy following negative staining with uranyl acetate.

$P A G E$ and protein blotting. Samples of insoluble, reconstituted fibril protein or total BC3 cell proteins were solubilized in SDS and electrophoresed in $15 \mathrm{~cm}$ long slabs of $15 \%(\mathrm{w} / \mathrm{v})$ polyacrylamide prepared essentially according to Laemmli (1970). After electrophoresis, gels were stained with Coomassie brilliant blue or blotted to nitrocellulose sheets in the presence of $4 \mathrm{M}$-urea (Bowen et al., 1980). Blots were stained with Coomassie brilliant blue (Townsend \& Archer, 1983) to check protein transfer and locate molecular weight markers.

Detection of antigens on blots. Nitrocellulose sheets were probed for bound antigens with antibody diluted 1 in 1000 (Townsend \& Archer, 1983). Protein-antibody complexes were located by incubating in a 1 in 2000 dilution of goat anti-rabbit IgG-horseradish peroxidase (Miles Laboratories; Towbin et al., 1979) and developed in the substrate 4-chloro-1-naphthol (Hawkes et al., 1982).

Embedding and thin sectioning. Fixed cells from $1 \mathrm{ml}$ suspension were sedimented by centrifugation and the pellet embedded in $1 \%(\mathrm{w} / \mathrm{v})$ agarose. Paraformaldehyde fixed pellets were processed for electron microscopy as described previously (Markham et al., 1974). Glutaraldehyde fixed pellets for immunogold staining were dehydrated at low temperature and embedded in Lowacryl K4M (Carlemalm et al., 1982) as described by Robertson et al. (1984). Sections were cut at a thickness of about $75 \mathrm{~nm}$ and placed directly on either 200 mesh gold grids to enable both section faces to be stained or on grids bearing carbon-parlodion films so that only the upper face of the section was stained.

Immunogold localization of p55 and p 25 in thin sections. Grids bearing sections were treated with antibody as described by Robertson et al. (1984). Pre-immune serum, anti-p25 antibody and non-cross-adsorbed anti-p55 serum were diluted 1 in 10 . Anti-p55 antibody was diluted 1 in 30 . Bound antibodies were localized by treatment with a 1 in 10 dilution of goat anti-rabbit IgG-gold $(5 \mathrm{~nm})$ (Janssen Pharmaceutica, Beerse, Belgium) and washed in TBS containing $0 \cdot 1 \%(\mathrm{w} / \mathrm{v})$ Triton X-100 (Robertson et al., 1984). Sections were post stained in uranyl acetate.

\section{RESULTS}

Reversible dissociation of spiroplasma fibrils. Maleylation of the amino groups caused dissociation of about $45 \%(\mathrm{w} / \mathrm{v})$ of the fibril protein. Regeneration of the amino groups by lowering the $\mathrm{pH}$ of the clear supernatant caused a light flocculant precipitate to form which was composed of 100-200 $\mathrm{nm}$ long spindle shaped pieces of re-assembled fibril aggregate showing the characteristic $8.5 \mathrm{~nm}$ axial repeat (Fig. 1). When the precipitate was solubilized in SDS and subjected to SDS-PAGE it migrated as a single band corresponding to a protein of mol. wt 55000 (results not shown).

Specificity of anti-p55 serum. Anti-p55 serum from the rabbit immunized with DMMA dissociated fibrils formed precipitin lines in agarose against homologous antigen and against fibrils solubilized in SDS and also gave weak positive reactions against whole BC3 cells solubilized in SDS (results not shown). However, anti-p55 serum caused loss of motility and cell deformation at dilutions up to 1 in 256 whereas pre-immune serum failed to deform cells at a dilution of 1 in 32, indicating that the immune serum contained antibodies binding to the cell surface. Since fibrils have been claimed to be endocellular structures (Townsend et al., 1980 b) we concluded that the anti-p55 serum was probably contaminated with antibodies elicited against cell surface antigens. To identify these antigens, blots of total SDS denatured BC 3 cell proteins were probed with anti-p55 serum. As well as p55, the anti-p55 serum reacted with a smaller protein of mol. wt 25000 (Fig. 2, track 1). This protein was recognized by anti-p25 antibody, identifying it as BC3 spiralin (Fig. 2, track 3). Anti-p25 antibody also reacted weakly with a higher molecular weight protein of unknown identity.

Cross-adsorption of anti-p55 serum. To remove antibodies against p25-spiralin the anti-p55 serum was cross-adsorbed against glutaraldehyde fixed spiroplasmas. Following crossadsorption the anti-p55 antibody no longer reacted with p25 but still reacted with p55 with undiminished efficiency (Fig. 2, track 2). 

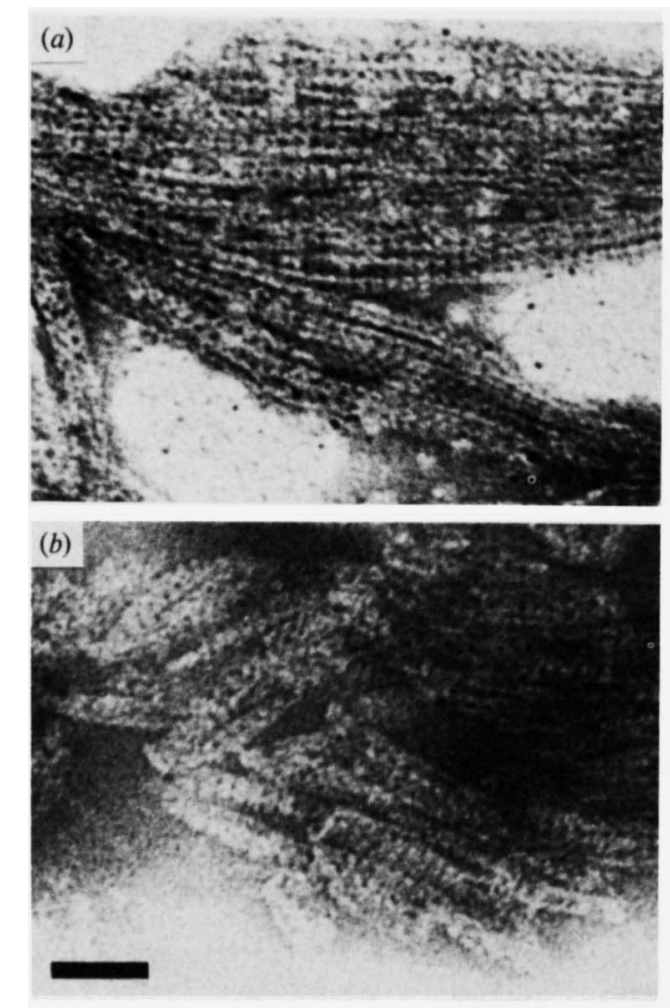

Fig. 1

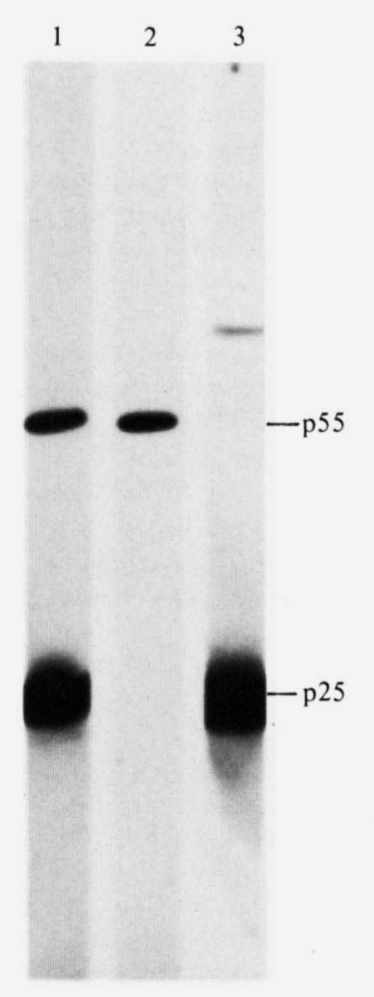

Fig. 2

Fig. 1. Purified spiroplasma fibrils before dissociation with DMMA (a) and after re-association at pH $6.0(b)$; the characteristic $8.5 \mathrm{~nm}$ axial repeat is evident in both samples. Bar, $50 \mathrm{~nm}$.

Fig. 2. Protein blots of total $\mathrm{BC} 3$ proteins probed with anti-p55 serum raised against DMMA dissociated fibrils before (track 1) and after (track 2) cross-adsorption against fixed BC 3 cells or (track 3) anti-p25 antibody.

The cross-adsorbed anti-p55 antibody failed to cause spiroplasma deformation at the lowest dilution tested ( 1 in 30$)$.

Immuno-ferritin localization of p25 on the cell surface. To confirm that anti-p55 antibody no longer reacted with p 25 surface antigen, fixed cells were immuno-ferritin stained with anti-p55 serum before and after cross-adsorption against fixed cells. Before cross-adsorption the anti-p55 serum localized p25 in discrete patches over the surface of the cell (Fig. $3 a$ ) whereas after crossadsorption anti-p55 antibody failed to stain any sites on the cell surface (results not shown).

The localization of p25 in discrete patches was at variance with a previous report (Archer \& Townsend, 1981) which showed that p25 antigen was uniformly distributed over the cell surface. We therefore repeated the immuno-ferritin staining with anti-p25 antibody and again observed uniform staining of the cell surface (Fig. $3 b$ ).

Immuno-ferritin labelling of native 55 in cell spreads. Kleinschmidt spreads of osmotically lysed cells were immuno-ferritin stained with cross-adsorbed anti-p55 antibody to confirm that the antibody recognized native protein. Anti-p55 antibody caused heavy staining of fibrils released from lysed cells (Fig. 3c). At a dilution of 1 in 100, the antibody stained fibrils less heavily, allowing their characteristic morphology to be discerned (Fig. 3d). No staining was observed when fibrils were exposed to anti-p25 antibody (Fig. 3e).

Immuno-ferritin localization of p55 in fixed, detergent extracted cells. Attempts to localize p55 in situ by permeabilizing paraformaldehyde fixed cells to antibodies were unsuccessful. Detergent 

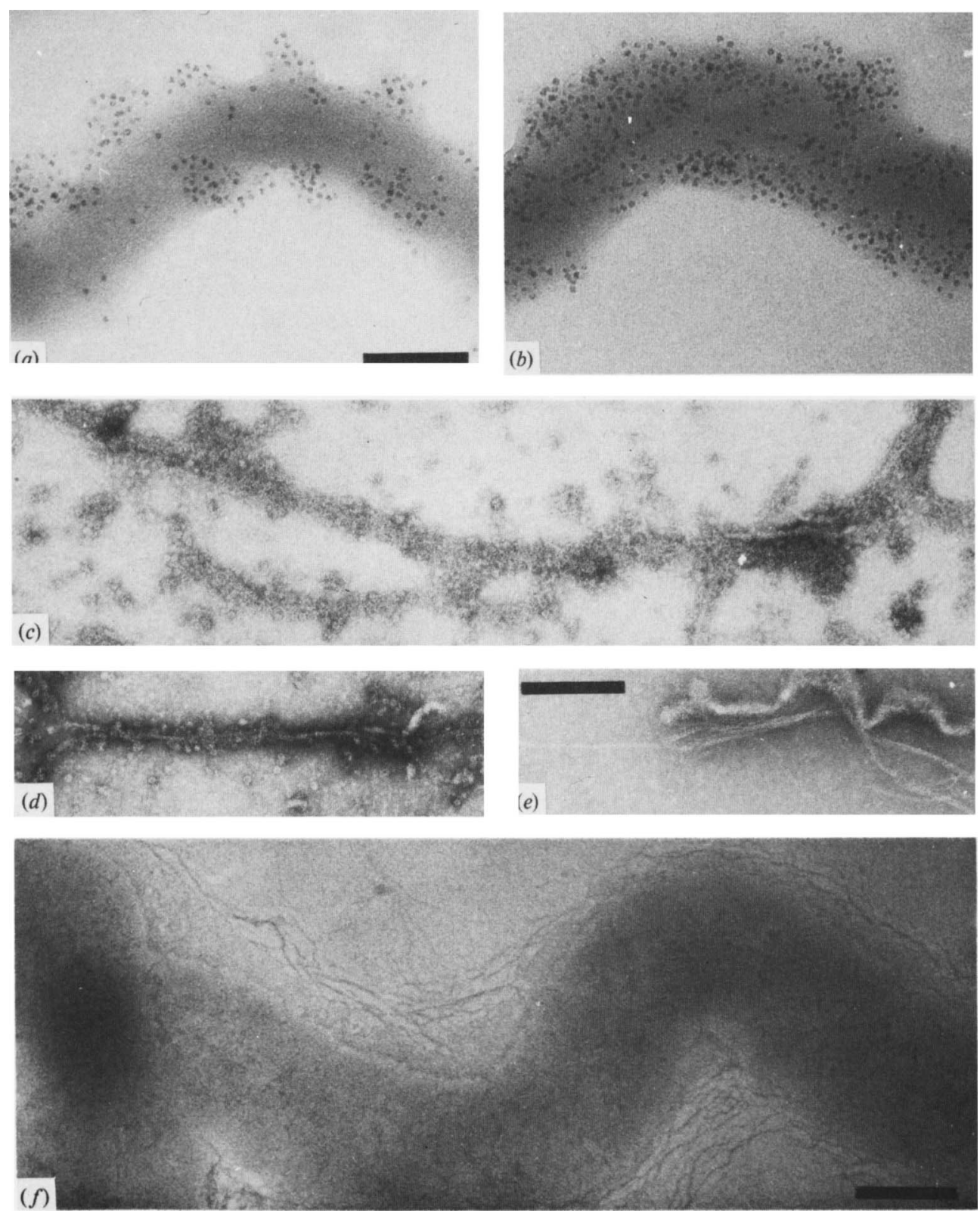

Fig. 3. Immuno-ferritin staining of spiroplasmas stained with (a) non-cross-adsorbed anti-p55 serum and $(b)$ anti-p25 antibody; bar $100 \mathrm{~nm}$. (c-e) Fibrils released from lysed cells immuno-ferritin stained with cross-adsorbed anti-p55 antibody, diluted $(c) 1$ in 10 and $(d) 1$ in 100 , or $(e)$ with anti-p25 antibody; bar, $200 \mathrm{~nm}$. ( $f$ ) Detail of the network of extracellular strands revealed by negative staining of SDS extracted cells; bar, $100 \mathrm{~nm}$.

treated cells bound large quantities of goat anti-rabbit IgG-ferritin non-specifically. However, cells extracted with SDS and to a lesser extent Triton X-100 showed a complex network of extracellular strands when negatively stained (Fig. $3 f$ ).

Thin sections of paraformaldehyde fixed cells. Paraformaldehyde fixation results in poor preservation of membranes because lipids are removed during subsequent processing but, as a consequence, it may be easier to discern structures which are closely associated with the 


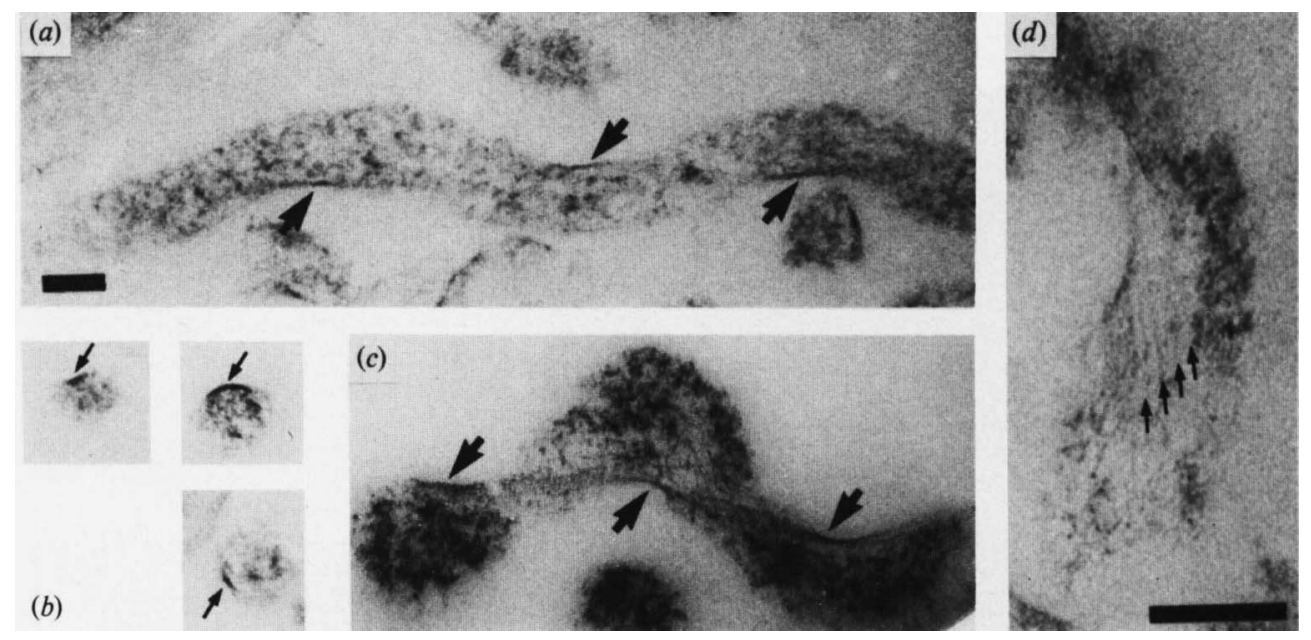

Fig. 4. (a-c) Thin sections of paraformaldehyde fixed spiroplasma cells showing the presence of a flat densely staining structure (arrowed) abutting the cytoplasmic face of the plasma membrane on the inner curvature of the helix; bar, $100 \mathrm{~nm}$. (d) Section showing the evidence of a ribbon of parallel fibrils (arrowed); bar, $100 \mathrm{~nm}$.

membrane. Some sections which passed along the longitudinal axis of the spiroplasma cell helix showed a discontinuous electron-dense layer abutting the cytoplasmic face of the plasma membrane on the inner curvature of each coil of the helix (Fig. $4 a, c$ ). In cross-sections of the cell filament this layer was crescent shaped and measured up to $10 \mathrm{~nm}$ between inner and outer surfaces (Fig. $4 b$ ). Thin sections cut in the plane of this layer suggested that it contained several thin parallel fibrils (Fig. $4 d$ ).

Immunogold localization of p55 and p25 on thin sections. Cross-sections of the cell filament, immunogold stained on one face with anti-p55 antibody as the primary antibody, showed gold particles localized in groups or short strings confined to one side of the cell (Fig. 5a-e). Most particles were located near the cytoplasmic face of the plasma membrane. Controls in which sections were stained with pre-immune serum instead of specific antibody showed no gold staining (Fig. $5 f$ ). Cross-sections stained with anti-p25 antibody became heavily labelled with gold particles around the circumference of the cell (Fig. $5 \mathrm{~g}$ ). A significant proportion of the gold particles appeared to be located on the cytoplasmic side of the plasma membrane

Extracellular strands of electron-dense material were often visible and appeared to be associated with the outer layer of the plasma membrane (Fig. $5 d-f$ ). They were not stained by anti-p 55 antibody but were stained by anti-p 25 antibody (Fig. $5 \mathrm{~g}$ ) and by non-cross-adsorbed anti-p55 serum (Fig. $5 h$ ).

Many sections revealed the presence of a complex network of intracellular threads. These were most evident in spherical swollen cells which occur with low frequency in most spiroplasma cultures (Townsend et al., 1980 b). The network of threads was not stained by reagents specific for p55 and p25. Sections passing through spherical cells and stained with anti-p25 antibody showed very clearly that p 25 was associated only with the plasma membrane.

Sections parallel to the longitudinal axis of the spiroplasma cell helix most clearly reflected the morphology of the organisms. When both faces of such sections were stained with anti-p55 antibody, groups of gold particles were localized at regular intervals along the cell filament corresponding to areas on the inner curvature of each coil of the helix (Fig. $6 a, b$ ). If similar profiles were stained with anti-p55 antibody on only one face of the section, the staining was either similar or no specific staining was observed. Some sections passing tangentially to the longitudinal axis of the cell helix showed gold particles in long strings (Fig. 6c). Occasionally sections passed through the tapered tip of a cell and exposed p55 antigen (Fig. $6 a$, inset).

Sections stained with anti-p25 antibody became heavily labelled at any point where the plasma membrane was exposed (Fig. 6d,e). 


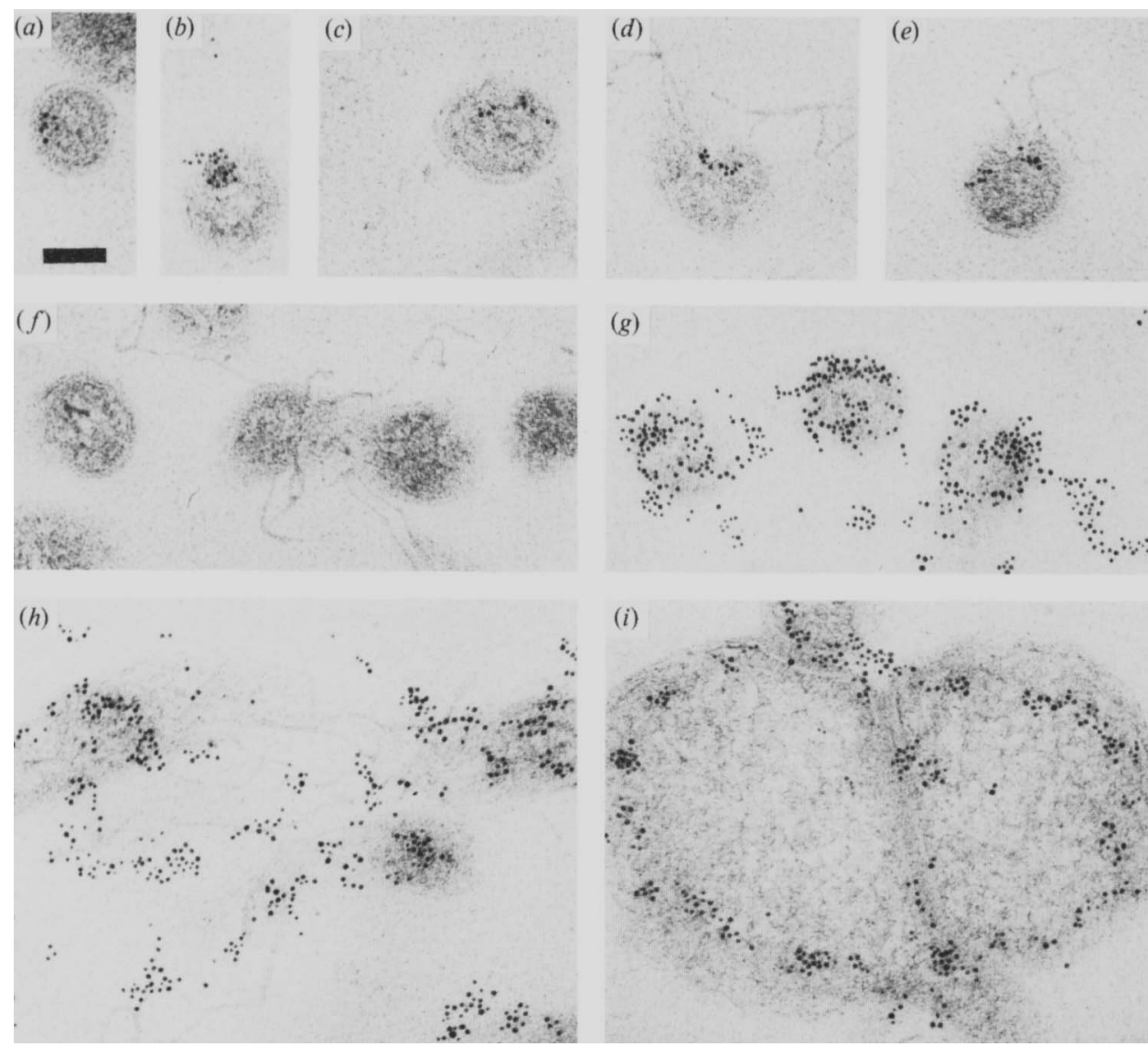

Fig. 5. Thin sections of spiroplasma cells after immunogold staining on one surface with $(a-e)$ anti-p 55 antibody, $(f)$ pre-immune serum or $(g)$ anti-p25 antibody. $(h)$ Section showing extracellular strands stained with non-cross-absorbed anti-p55 serum and $(i)$ section through a pair of swollen cells stained with anti-p25 antibody. Bar, $100 \mathrm{~nm}$.

\section{DISCUSSION}

We interpret the internal layer seen in thin sections of paraformaldehyde fixed cells as representing a helically twisted ribbon which follows the inner curvature of the spiroplasma cell (i.e. it maintains a position proximal to the longitudinal axis of the helix) as represented diagramatically in Fig. 7(a). We believe that this may be the same structure observed in $S$. citri cells by Cole et al. (1973) who described an additional discontinuous internal layer, $6.7 \mathrm{~nm}$ wide but of variable length, abutting the cytoplasmic membrane and which appeared membrane-like but had an obvious internal content occasionally suggesting cross-striations. Our own observation of fibres within this layer strongly suggests that the ribbon is composed of spiroplasma fibrils. This conclusion is supported by the distribution of $\mathrm{p} 55$ fibril protein as demonstrated by immunogold staining with anti- 55 antibody.

Since the overall diameter of the spiroplasma helix is about $350 \mathrm{~nm}$ and sections were cut at a thickness of about $75 \mathrm{~nm}$, a section such as that represented in Fig. 7(a), in which one face passes along the longitudinal axis of the cell helix, would expose a series of oval shaped profiles representing the coils of the helix as they loop in and out of the section (Fig. $7 b$ ). On the opposite face, a corresonding series of elliptical shaped profiles would be exposed representing the outer part of each coil (Fig. $7 a$ ). When both faces of the section were stained with anti-p55 antibody, p55 was localized on the inner coil of each turn of the helix where our model predicts the fibril ribbon would be exposed; compare Fig. 6(a) with Fig. 7(b). When only one face of the section 

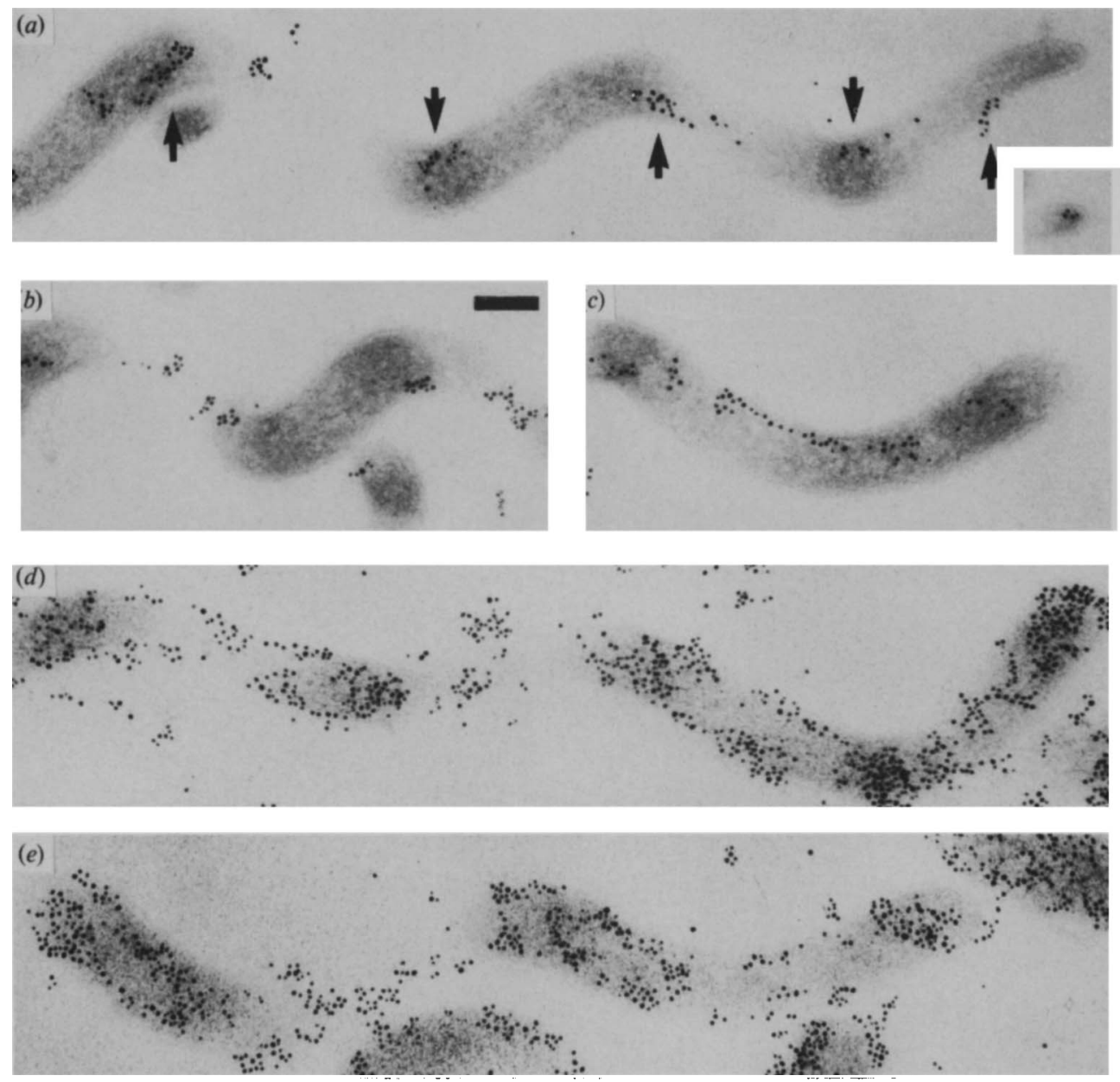

Fig. 6. Thin sections of spiroplasma cells after immunogold staining on both surfaces with $(a-c)$ antip55 antibody and $(d, e)$ anti-p 25 antibody; bar, $100 \mathrm{~nm}$. Arrows on $(a)$ facilitate comparison with Fig. $7(b)$.

was stained, some profiles showed no staining for $\mathrm{p} 55$, these presumably represent profiles of the outer parts of coils through which the ribbon does not pass (Fig. 7a). Sections tangential to the longitudinal axis of the helix in which p 55 was localized in long strings probably cut obliquely across the ribbon, while cross-sections of the cell filament cut across the ribbon at an acute angle so that p55 was localized near the plasma membrane on one side of the cell cross-section. The tendency of the gold reagent to occur in clusters made it difficult to find representative sections which unequivocally showed an intimate association of $\mathrm{p} 55$ with the cytoplasmic face of the plasma membrane.

We believe that the fibril ribbon runs the entire length of the cell; p55 was localized in the tapered tip structure which is transient and probably represents a site of recent cell division (Garnier et al., 1984). The opposite end of such cells is blunt, as revealed by negative staining (Garnier et al., 1984) and so cannot be identified with certainty in thin sections because of the flexuous nature of spiroplasmas.

While individual fibrils appear to lack the rigidity necessary to determine cell shape, their proximity within the ribbon could facilitate mutual interaction to form a semi-rigid structure capable of maintaining the helical shape of the spiroplasma cell. Kleinschmidt spreads of spiroplasma cell contents suggest that the cellular complement of fibrils is only four or five pairs 


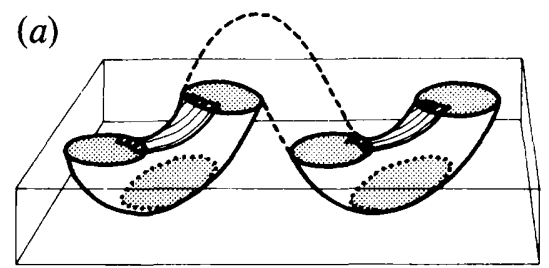

(b)

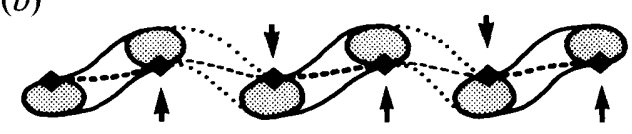

Fig. 7. Diagramatic representations of $(a)$ a section $75 \mathrm{~nm}$ thick, in which the upper plane passes along the longitudinal axis of the cell helix, showing the cell profiles exposed on either face of the section (shaded) and the position of the endocellular fibril ribbon and $(b)$ cell profiles exposed on one face of a longitudinal section showing the position of the fibril ribbon and the points at which p 55 antigen will be exposed (arrowed and $\bullet$ ).

which associate in a single ribbon; however, the isolated ribbon shows no evidence of helicity (Townsend, 1983a), suggesting that the generation of a helix requires interaction with other cell components. Maintenance of helical morphology by a single twisted ribbon implies that an alternative system is responsible for maintaining the filamentous form of the cell. Furthermore, it is difficult to envisage how the fibril ribbon could generate the rotary twisting movements which characterize spiroplasma motility.

The asymmetric distribution of p55 in cross-sections of the cell filament is consistent with the arrangement of fibrils in a ribbon and is clearly inconsistent with the model of arrangement and function which proposed that fibrils were helically wound around the cytoplasmic face of the plasma membrane to form a contractile sheath (Razin, 1978; Townsend et al., 1980 b). Furthermore, we found no evidence that p55 forms part of a cytoskeleton consisting of an endocellular axial filament with lateral branches connecting to the cell membrane (Wilson \& Goodman, 1982). A complex network of intracellular threads was apparent in many sectioned cells but this network did not stain positively for $\mathrm{p} 55$ or $\mathrm{p} 25$, supporting the generally accepted interpretation that the network is composed of condensed nucleic acid (Cole et al., 1973; Waters, 1982).

Wróblewski (1981) has proposed that despite its low molecular weight (26000), spiralin forms diameters which are able to span the $S$. citri plasma membrane. Because of the clustering of the gold reagent we were able to demonstrate convincingly that p25-spiralin was present on both surfaces of the $\mathrm{BC} 3$ plasma membrane. Transmembrane distribution of p25-spiralin can be inferred, however, from distribution on p25 demonstrated by immuno-ferritin labelling of surface antigens (Fig. $3 b$ ) and by immunogold localization of p 25 on cross-sections of the cell filament (Fig. $5 g$ ).

A proportion of p25 spiralin-like protein is in the form of loosely associated extracellular strands which may arise from discrete areas on the cell surface and could be related to the network of strands revealed by detergent extraction of fixed cells. The filamentous nature of this material may account for its co-purification with spiroplasma fibrils resulting in the production of antibodies to both p55 and p25. Although p25 was not detected in the antigen preparation by PAGE, we have previously commented on the highly antigenic nature of this protein (Townsend \& Archer, 1983). The presence of these extracellular strands is of significance in the light of several reports of variable and poorly defined extracellular layers around spiroplasmas which disappear when cells are extensively washed or membranes are prepared (Horne, 1970; Cole et al., 1973; Razin et al., 1973). Furthermore, differences in the distribution of $\mathrm{p} 25$ on the surface of cells, revealed by immuno-ferritin staining with antibodies elicited against p25 co-purifying with fibrils and antibodies to the intrinsic membrane protein (Archer \& Townsend, 1981), suggest that the fibrous form of p25 represents a different epitope.

The use of p55 as a spiroplasma specific marker and its detection at a threshold level of about $10^{6}$ organisms per $\mathrm{g}$ tissue was reported by Townsend (1983b). Immunogold staining offers the possibility of disease diagnosis based on appropriate localization of specific antigen in a single organism within a tissue sample. 
We thank Mr B. Wells for the preparation of cell spreads, Dr D. B. Archer for advice on the use of DMMA and Dr J. Robertson for his assistance and advice on immunogold staining. This work was done under Ministry of Agriculture, Fisheries and Food licence no. PHF 49/41.

\section{REFERENCES}

ARCHER, D. B. \& TownSEND, R. (1981). Immunoelectrophoretic separation of spiroplasma antigens. Journal of General Microbiology 123, 61-68.

Bowen, B., Steinberg, J., Laemmli, U. K. \& Weintraub, H. (1980). The detection of DNAbinding proteins by protein blotting. Nucleic Acids Research 8, 1-20.

Butler, G., Harris, J. I., Hartley, B. S. \& LEBERMAN, R. (1967). Reversible blocking of peptide amino groups by maleic anhydride. Biochemical Journal 103, 78P.

Carlemalm, E., Garavito, R. M. \& Villiger, W. (1982). Resin development for electron microscopy and an analysis of embedding at low temperature. Journal of Microscopy 126, 123-143.

Cole, R. M., Tully, S. G., Popkin, T. J. \& Bové, J. M. (1973). Morphology, ultrastructure and bacteriophage infection of the helical mycoplasma-like organism (Spiroplasama citri, gen. nov., sp. nov.) cultured from 'stubborn' disease of citrus. Journal of Bacteriology 115, 367-386.

Crowle, A. J. (1961). Immunodiffusion. New York: Academic Press.

Dixon, H. B. F. \& Perham, R. N. (1968). Reversible blocking of amino groups with citraconic anhydride. Biochemical Journal 109, 312-314.

Garnier, M., Clerc, M. \& Bové, J. M. (1984). Growth and division of Spiroplasma citri: elongation and elementary helices. Journal of Bacteriology 158, 23-28.

GerTler, A. (1971). Selective, reversible loss of elastolytic activity of elastase and subtilisin from electrostatic changes due to maleylation. European Journal of Biochemistry 23, 36-40.

Hawkes, R., Niday, E. \& Gordon, J. (1982). A dotimmunobinding assay for monoclonal and other antibodies. Analytical Biochemistry 119, 142-147.

HoRne, R. W. (1970). The ultrastructure of mycoplasma and mycoplasma-like organisms. Micron 2, 19-38.

K LEINSCHMIDT, A. K. (1968). Monolayer techniques in electron microscopy of nucleic acid molecules. Methods in Enzymology 22, 361-377.

LAEMMLI, U. K. (1970). Cleavage of structural proteins during the assembly of the head of bacteriophage T4. Nature, London 227, 680-685.

Markham, P. G., TownSend, R., Bar-Joseph, M., Daniels, M. J., Plaskitt, K. A. \& Meddins, B. M. (1974). Spiroplasmas are the causal agents of citrus little-leaf disease. Annals of Applied Biology 78, 4957.

Palacíá, E. (1979). Solubilisation of membranebound transpeptidase from Streptomyces strain K-11 with 2,3-dimethylmaleic anhydride. Revista espanola de fisiologia 35, 481-484.
RazIN, S. (1978). The Mycoplasmas. Microbiological Reviews 42, 414-470.

Razin, S., Hasin, M., Ne'eman, Z. \& Rottem, S. (1973). Isolation, chemical composition and ultrastructural features of the cell membrane of the mycoplasma-like organism Spiroplasma citri. Journal of Bacteriology 116, 1421-1435.

Robertson, J. G., Wells, B., Bisseling, T., FARnden, T., Farnden, K. J. F. \& Johnston, A. W. B. (1984). Immuno-gold localisation of leghaemoglobin in the plant cytoplasm in nitrogen-fixing root nodules of pea. Nature, London 311, 254-256.

Towbin, H., Staehelin, T. \& Gordon, J. (1979). Electrophoretic transfer of proteins from polyacrylamide gels to nitrocellulose sheets: procedure and some applications. Proceedings of the National Academy of Sciences of the United States of America 76, 4350-4354.

TOWNSEND, R. $(1983 a)$. Spiroplasma fibrils. Yale Journal of Biology and Medicine 56, 447-452.

TownSEND, R. (1983b). Mycoplasma-like organisms from plants with 'yellows' diseases lack a spiroplasma-specific antigen. Journal of General Microbiology 129, 1959-1964.

TOWNSEND, R. \& ARCHER, D. B. (1983). A fibril protein antigen specific to Spiroplasma. Journal of General Microbiology 129, 199-206.

Townsend, R., ArCher, D. B. \& Plaskitt, K. A. $(1980 a)$. Purification and preliminary characterisation of spiroplasma fibrils. Journal of Bacteriology 142, 694-700.

Townsend, R., Burgess, J. \& Plaskitt, K. A. $(1980 \mathrm{~b})$. Morphology and ultrastructure of helical and nonhelical strains of Spiroplasma citri. Journal of Bacteriology 142, 973-981.

WATERS, H. (1982). Light and electron microscopy. In Plant and Insect Mycoplasma Techniques, pp. 101151. Edited by M. J. Daniels \& P. G. Markham. London: Croom Helm.

Williamson, D. L., Whitcomb, R. F. \& Tully, J. G. (1978). The spiroplasma deformation test, a new serological method. Current Microbiology 1, 203-207.

WILSON, H. J. \& GoOdMAN, R. M. (1982). A framework for motility and morphology of spiroplasmas. In Abstracts of the Annual Meeting of the American Society for Microbiology, 1982. Washington, DC: American Society for Microbiology.

WRóBLEWSKI, H. (1981). Electrophoretic analysis of the arrangement of spiralin and other major proteins in isolated Spiroplasma citri cell membranes. Journal of Bacteriology 145, 61-67.

Wróblewski, H., Johansson, K.-E. \& Huerten, S. (1977). Purification and characterisation of spiralin, the main protein of the Spiroplasma citri membrane. Biochimica et biophysica acta 465, 275-289. 